\title{
EXTENSION OF IEC'S GENERIC DATA ACCESS WITH A LOCKING MECHANISM
}

\author{
VukMirovic, S.; ERdelJAN, A.; LENDAK, I. \& CAPKO, D.
}

Abstract: This paper proposes an extension of IEC's Generic Data Access standard (GDA) which allows safer multi-user work. This is achieved by locking the resources and/or resources associated with them before starting to edit them. Locking can eliminate data inconsistencies and conflicts generated in multi-user environments and thereby allow faster data entering. Another important benefit of this solution is the implicit locking of larger portions of the model. The GDA defines a set of simple interfaces allowing access to data from any data model. The new set of functions proposed in this paper allows clients to lock and unlock resources, get the list of locked resources or check whether a specific resource is locked. The paper describes a solution that is universal and configurable, allowing locking rules to be changed without changing the source code of the GDA server. The new interface is implemented and tested in industry environment.

Key words: generic data access, data locking, utility management system
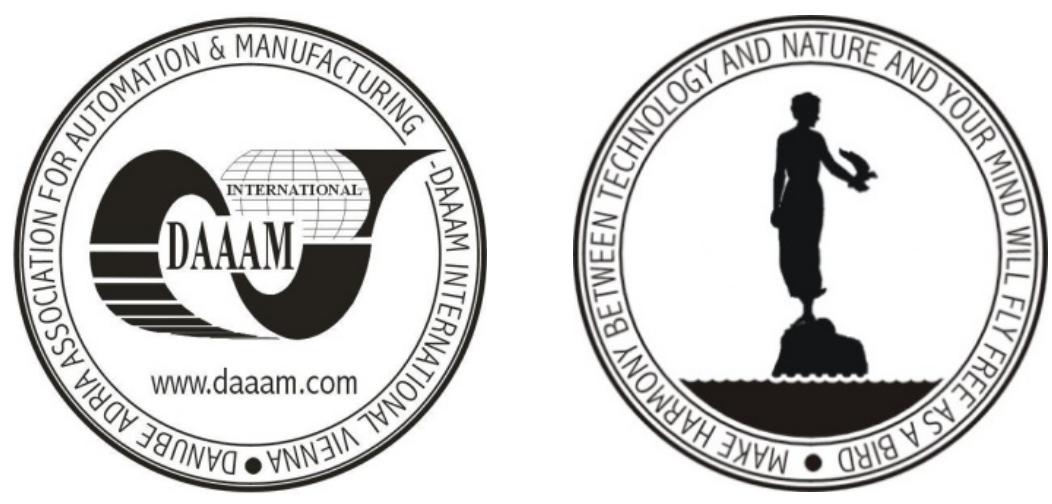

Authors' data: Msc. Vukmirovic, S[rdjan]; Dr. Sc. Erdeljan, A[leksandar]; Msc Lendak I[mre]; Msc Capko D[arko], Faculty of Technical Sciences, University of Novi Sad, Trg Dositeja Obradovica 6, 21000, Novi Sad, Serbia, srdjanvu@uns.ac.rs, ftn_erdeljan@uns.ac.rs, lendak@uns.ac.rs,dcapko@uns.ac.rs

This Publication has to be referred as: Vukmirovic, S[rdjan]; Erdeljan, A[leksandar]; Lendak I[mre] \& Capko D[arko] (2009). Extension of IEC's Generic Data Access With a Locking Mechanism, Chapter 26 in DAAAM International Scientific Book 2009, pp. 241-250, B. Katalinic (Ed.), Published by DAAAM International, ISBN 978-3-901509-69-8, ISSN 1726-9687, Vienna, Austria

DOI: $10.2507 /$ daaam.scibook.2009.26 